\title{
CPD certification of Sri Lankan doctors
}

\section{S Seneviratne Epa}

The following frequently asked questions and their answers, related to the CPD certification of Sri Lankan doctors, are being published in concurrence with the Central CPD Committee of all medical professional colleges and associations of Sri Lanka.

\section{What is CPD?}

CPD refers to Continuing Professional Development, a process that enables you to engage in good medical practice.

\section{What is good medical practice?}

This is defined by the GMC (General Medical Council of the UK) under seven headings as follows:

1. Good clinical care.

2. Maintaining good medical practice.

3. Teaching and training.

4. Relationship with patients.

5. Working with colleague.

6. Probity.

7. Caring for your own health.

\section{Does it mean, good medical practice is not only looking after patients well?}

Yes. It encompasses a much broader meaning.

\section{Why is CPD necessary? Can't a doctor engage in good medical practice without CPD?}

Needs of the patients, doctors and of the health service within which they practice keep changing with time. So being up to date with theses changes is necessary if a doctor is to engage in good medical practice.

\section{How can one make sure that a doctor participates in CPD?}

In developed countries CPD has been made a legal requirement by linking it to doctors' registration to practice. This process is called revalidation. The latest countries to introduce revalidation are the UK and Singapore.

\section{In a country like Sri Lanka where revalidation is not acceptable, how can we ensure that doctors participate in CPD voluntarily?}

The first requirement is that opportunities for CPD must be made available, especially to those practicing in remote areas. This is why we are introducing a National Programme of CPD, with the help of the Ministry of Healthcare.

The proposed CPD certificate will be an incentive to participate in this programme.

\section{What is the value of such a CPD Certificate?}

1. Most important is that it will give a doctor the satisfaction that he or she is updated and will enhance self-esteem.

2. Display of such a certificate at doctor's practice will inform the public that the doctor is competent and updated.

3. In a court of law it is likely to give some protection (though not legally binding) to the doctor in medical litigation as compared to a doctor who does not possess such a certificate. 


\section{How do you propose to do this?}

We have already set up a Central CPD Committee (CCPD COM) of all Colleges and Associations, including the Government Medical Officers' Association (GMOA). A National Center for CPD in Medicine (NCCPDM) will be established, and this will be run by the CCPD COM.

\section{How does it work in the periphery?}

In each district a District CPD Centre (DCPDC) will be established under a District CPD Committee (DCPD COM). DCPD COM will have a representation from all categories of doctors in a district including dental and preventive services. All DCPDCs will work under guidance from the NCCPDM.

\section{What are the functions of a DCPDC?}

DCPDC will be responsible for organising adequate and appropriate CPD programmes of good quality. For this purpose, NCCPDM will issue guidelines. DCPDCs will be recommending the names of those who complete the CPD point criteria to the NCCPDM for the award of the CPD Certificate.

\section{What should a doctor do if he or she wishes to get a CPD Certificate?}

Doctors should register with the respective DCPDC and obtain a portfolio to enter the activities, together with the allocated credit points for each activity. At the end of the stipulated period of one year, he or she should apply to the DCPDC for the CPD Certificate by submitting a copy of the entries in the portfolio.

\section{Who gives the credit points?}

Doctors themselves give the points and enter in their portfolios against each activity based on the point scheme published by the NCCPDM.

\section{How many credit points should a doctor earn for a year, and will all doctors, especially those in remote places, be able to do so?}

We expect 50 credit points for a year, based on the assumption of a minimum of 50 hours of CPD activities for a year by a doctor. This is the currently accepted standard elsewhere. We have made the point scheme a doctor-friendly one, so that even the remotest doctor is able to earn the required points.

\section{Is this scheme meant for a particular category of doctors such as consultants or grade medical officer, etc?}

No. Any doctor with MBBS and registered with the Sri Lanka Medical Council (SLMC), irrespective of designation or the sector (state or private), will be eligible. However, consultants are expected to select their specialty as the core area and are expected to score a minimum of $20 \%$ ( 10 core points/year) of credit value from core activities as recognised by the DCPDC (e.g. activities organised by the respective Colleges or Associations of their specialties). Doctors are expected to inform the DCPDC of their selected core areas.

\section{Can a grade medical officer or a general practitioner also select a core area?}

Yes. Any doctor can select a core area (an area of their interest) provided he or she is confident that 10 core points/ year can be scored in that particular area.

\section{Is there any advantage in selecting a core area for non-specialist doctor?}

Yes. If one selects a core area, this would be indicated on the CPD Certificate. So in a job interview or any other competitive situation, having a core area mentioned on the certificate will be an advantage. A list of core areas will be published. 


\section{Aren't doctors likely to record activities in which he or she did not participate?}

This is a voluntary scheme and we expect honesty on the part of doctors (it is also a part of good medical practice as defined above). However, DCPDC will be checking logbook records on a random basis to ascertain the accuracy of entries. There will be a way to check on such entries: for example, all participants in an organised activity are expected to sign an attendance register to be maintained by the DCPDCs in future.

\section{Who is funding this programme?}

Ministry of Health $(\mathrm{MOH})$ is prepared to fund this at the moment, and in future we will be turning to other donor agencies as well.

\section{In addition to the CPD certificate what are the other benefits of having a national CPD programme?}

We expect doctors' educational facilities to be improved. We expect government doctors to get duty leave and other facilities to attend training programmes both within and outside districts. When computers are made available with funds, e-learning will be a major part of this programme, especially in the periphery.

\section{What is the role of medical professional Colleges and Associations in this programme?}

Specialist Colleges and Associations are expected to intensify their activities as their members would select respective specialties as the core areas in their CPD certificates. For this purpose all activities organised by colleges and associations will be recognised as core activities for the respective specialties by the DCPDCs. This would also provide an opportunity to those professional bodies to popularise their specialties among non-consultants (non-members).

\section{Will there be an international recognition of this CPD certificate?}

CPD is now being recognised as an essential part of medical profession worldwide. There is no guarantee of any international recognition for our certificate at the moment. However, recent reference to our programme in a leading article in the British Medical Journal (3rd April 2004, p. 779) clearly shows the interest the rest of the world has in our programme. This is because we are the first in the South Asia to organise such a national CPD programme for doctors. We are, therefore, optimistic of obtaining some form of international recognition for our CPD certificate in future.

Chairman, Central CPD Committee, No 7, Wijerama Mawatha, Colombo 7, Sri Lanka. 